\title{
Dietary Intake, Nutrition, and Fetal Alcohol Spectrum Disorders in the Western Cape Province of South Africa
}

\author{
Philip A. May, Ph.D. ${ }^{1,2}$, Kari J. Hamrick, Ph.D. ${ }^{3}$, Karen D. Corbin, Ph.D., RD ${ }^{1}$, Julie Hasken, \\ M.P.H. ${ }^{1}$, Anna-Susan Marais, B. Cur. Nursing ${ }^{4}$, Lesley E. Brooke, B.S. (Hons) ${ }^{5}$, Jason \\ Blankenship, Ph.D. ${ }^{2}$, H. Eugene Hoyme, M.D. ${ }^{6}$, and J. Phillip Gossage, Ph.D. ${ }^{2}$ \\ ${ }^{1}$ University of North Carolina at Chapel Hill, Nutrition Research Institute, Gillings School of Global \\ Public Health, USA \\ ${ }^{2}$ The University of New Mexico Center on Alcoholism, Substance Abuse, and Addictions \\ (CASAA), Albuquerque, USA \\ ${ }^{3}$ Navigate Nutrition Consulting, PLLC, Seattle, USA \\ ${ }^{4}$ Stellenbosch University, Faculty of Health Sciences, Tygerberg, ZA \\ ${ }^{5}$ Formerly with the University of Cape Town, Foundation for Alcohol Related Research (FARR), \\ Cape Town, ZA \\ ${ }^{6}$ Sanford School of Medicine, The University of South Dakota, Sioux Falls, USA
}

\begin{abstract}
In this study, we describe the nutritional status of women from a South African community with very high rates of fetal alcohol spectrum disorders (FASD). Nutrient intake (24-hours recall) of mothers of children with FASD was compared to mothers of normal controls. Nutrient adequacy was assessed using Dietary Reference Intakes (DRIs). More than 50 percent of all mothers were below the Estimated Average Requirement (EAR) for vitamins A, D, E, and C, thiamin, riboflavin, vitamin $\mathrm{B}_{6}$, folate, calcium, magnesium, iron, and zinc. Mean intakes were below the Adequate Intake (AI) for vitamin K, potassium, and choline. Mothers of children with FASD reported significantly lower intake of calcium, docosapentaenoic acid (DPA), riboflavin, and choline than controls. Lower intake of multiple key nutrients correlates significantly with heavy drinking. Poor diet quality and multiple nutritional inadequacies coupled with prenatal alcohol exposure may increase the risk for FASD in this population.
\end{abstract}

\section{Keywords}

fetal alcohol spectrum disorders; dietary intake; nutrition; pregnancy and alcohol; South Africa

\footnotetext{
(C) 2014 Elsevier Inc. All rights reserved.

Corresponding Author: Philip A. May, Ph.D., UNC Nutrition Research Institute, Gillings School of Global Public Health, 500 Laureate Way, Room 3229, Kannapolis, NC 28081, phone: 704-250-5002, fax: 704-250-5036, philip_may@unc.edu.

Publisher's Disclaimer: This is a PDF file of an unedited manuscript that has been accepted for publication. As a service to our customers we are providing this early version of the manuscript. The manuscript will undergo copyediting, typesetting, and review of the resulting proof before it is published in its final citable form. Please note that during the production process errors may be discovered which could affect the content, and all legal disclaimers that apply to the journal pertain.
} 


\subsection{Nutrition Status and Alcohol Consumption in South African Populations}

During pregnancy, maternal alcohol consumption and dietary intake may have a profound impact on the health and development of the fetus. Malnutrition, food insecurity, and risky drinking patterns are pervasive in certain segments of the population of South Africa (ZA) [1-10]. Low vitamin A intake, iron deficiency anemia, and stunted growth all represent significant health concerns for ZA [11]. Nutritional inadequacies in school-aged children are common, resulting in underweight (16.8\%), wasted (2.5\%), and stunted (23.5\%) growth [12-13].

Additionally, alcohol use among pregnant women is a major concern. Nearly half (42.8\%) of pregnant women surveyed in a Western Cape Province (WCP) study reported drinking alcohol during pregnancy, and over half who drank consumed enough alcohol to place their unborn children at "high risk" for fetal alcohol syndrome (FAS) [7]. The prevalence of fetal alcohol spectrum disorders (FASD) in the Western and Northern Cape Provinces of ZA is among the highest in the world (135.1 to 207.5 per 1000) [14-18], many times higher than prevalence estimates for the United States and Europe [19].

Alcohol and food absorption are affected by multiple factors including: concurrent consumption, sex, hormones, pregnancy, and/or disease status. While food intake can, in the short term, exert a protective effect from the toxic effects of alcohol consumption [20-22], alcohol consumption over time can adversely affect the quality and quantity of proper nutrient supply and energy intake, particularly for women $[23,24]$. Dietary intake among heavy drinkers is generally considered poor [25]. A recent study of Ukrainian and Russian mothers found lower mean blood plasma levels for most minerals and significant differences in zinc and copper between drinking mothers and non-drinking mothers [26].

Poor maternal nutrition during the prenatal period can cause low birth weight $[27,28]$. Dietary intake and alcohol consumption during breastfeeding (median duration 18 to 24 months in ZA) may place newborns at an additional disadvantage due to inadequate delivery of nutrients through breastmilk and exposure to alcohol, a known teratogen [29]. The teratogenic effects of alcohol are increased under certain micronutrient deficiencies such as iron [30], zinc [26], and choline [31,32]. Chronic alcohol use can affect micronutrient absorption and availability [33], but less is known about the effect of binge drinking (sporadic or regular drinking of four or five drinks or more per occasion). However, adequate nutrient intake may partially mitigate the harmful effects of alcohol on fetal development. Vitamin $\mathrm{B}_{3}$, folic acid, zinc, iron, and choline have all been shown to prevent and/or mitigate some of the effects of prenatal alcohol exposure [30,31,34,35].

\subsection{Impetus of this study}

In three separate samples in this study community, the body mass index (BMI) of mothers of children with FASD was found to be significantly lower than that of controls, and mothers of children with FASD in most populations have been disproportionally of lower socioeconomic status (SES) $[8,9,15,16,18,36]$. Dietary intake or other nutrition analyses have not been previously undertaken for mothers of children diagnosed with an FASD. This paper examines dietary and alcohol intake of mothers in a community in the WCP of ZA. 
Two questions are addressed. First, what proportion of the overall community maternal sample is likely deficient on essential macro and micronutrients? Second, is there a significant difference in dietary intake between mothers of children with FASD and mothers of controls?

\section{METHODS}

\subsection{Data collection and instruments}

The data in this paper originate from a nested study in a larger epidemiologic inquiry of the prevalence and characteristics of FASD in a community in ZA. A two-tiered process in elementary schools, described fully elsewhere $[8,15,18]$, identified children with FASD and randomly-selected, verified, not-FASD controls. All children in first grade classrooms of all thirteen community primary schools were screened for height, weight, and occipitofrontal head circumference (OFC). All children who were $\leq 10^{\text {th }}$ centile in height and weight and/or $\leq 10^{\text {th }}$ centile in OFC and randomly-selected candidates for normal controls received a standardized, comprehensive evaluation, including: 1) independent dysmorphology examinations by at least two dysmorphologists and 2) assessment of IQ, behavioral, and neuropsychological functioning via a battery of eleven tests/scales [37,38]. Biological mothers of children suspected to have an FASD and of the control children were interviewed on maternal risk variables including: use of alcohol at time of interview and during gestation of the index child [8]. Final diagnoses were assigned at a case conference where all findings (child physical, cognitive/behavioral, and maternal risk factors) were reviewed and weighed using revised Institute of Medicine (IOM) criteria [39,40]. If randomly-selected children were found to have an FASD, they were removed from the control group and placed into the FASD group. In this sample, there were 43 children with FASD ( 24 children diagnosed with FAS, 14 with PFAS (partial fetal alcohol syndrome), and 5 with ARND (alcohol-related neurodevelopmental deficits)) and 85 normal children for comparison.

\subsection{Dietary information}

Drinking data, current and past, were gathered via a structured interview with the mothers utilizing a time-line, follow-back technique [41,42] to collect multiple measures of drinking. Current drinking questions established a baseline of alcohol use and aid in accurate calibration and recall of drinking. Subsequent questions explored drinking 3 months prior to pregnancy and during each trimester of the index pregnancy. Photographs of the most popular sizes and brands of each type of local alcoholic beverage were used to standardize ethanol units (one standard drink equals $340 \mathrm{~mL}$ can/bottle of beer ( $5 \%$ ethanol), $120 \mathrm{~mL}$ of wine (11\% ethanol), $95 \mathrm{~mL}$ of wine (13.5\% ethanol) or $44 \mathrm{~mL}$ of distilled spirits (43\% ethanol)) $[43,44]$.

Dietary intake data originate from the maternal risk factor questionnaire and were neither analyzed nor utilized prior to case conference and the assignment of a final diagnosis. Each respondent was queried about food and liquid consumption in a 24-hour dietary recall $[45,46]$. Field interviewers asked detailed questions to ascertain everything each woman drank or ate in the day preceding her interview by portion size, type, preparation, and seasoning. Data were entered into NDSR (version 4.04/32) to obtain estimated nutrient 
intake for each woman. Having collected baseline information, the interviewer then asked each woman to recall the time of her pregnancy with the index child and to reflect on how her current (preceding day) food and beverage intake was similar to or different from the time of her pregnancy. The 24-hour recall method is a commonly used method for dietary surveys. They have been used frequently in African and South African populations [46]. Additional questions assessed the availability of food within the household at the time of that pregnancy.

\subsection{Data analysis}

Epi-Info software and SPSS were used to input and analyze the data. Chi-square tests were calculated on frequencies for nominal or ordinal-level data, and z-tests and difference of means tests were utilized for interval-level measures to determine difference between study groups. Pearson product-moment correlations were used to determine associations between particular nutrients and alcohol use. Because this is a first exploratory study of nutrition effecting diagnoses of FASD in humans, an alpha level of .05 (two-tailed) was used for determining significance for case control comparison and for correlations, as this study attempted to explore any possible association between nutrition and risk for FASD. Therefore, the alpha of .05 reduces the risk for Type II error (failing to reject a false, null hypothesis), but increases the likelihood of a Type I error (accepting a false, null hypothesis).

Dietary intakes were compared with the Dietary Reference Intakes (DRIs) established by the IOM [47]. The Estimated Average Requirements (EARs) are defined to be an intake that meets the nutritional needs for $50 \%$ of individuals in a specific gender and life stage. If there is not sufficient evidence for an EAR to be established, an Adequate Intake (AI) is established. Recommended Dietary Allowance (RDA) is defined to meet the nutritional needs of $97-98 \%$ of healthy individuals in a specific gender and life stage. If less than 50\% of the sample had nutrient intake below EAR or the mean intake was below AI, we classified the intake to be likely inadequate. If an observed nutrient intake is above the RDA, the observed intake is considered to likely be adequate. Due to extreme variation among individuals of the same sex and ages, and because of the necessity to estimate adequate pregnancy intake from interviews conducted when the subjects were often not pregnant, conclusions about the intake adequacies for nutrient intake between EARs and RDA cannot be easily made [48].

Table 3 represents a link of the post-hoc interviews to the index pregnancy. Due to the intercorrelations of energy requirements and energy intake (e.g. higher energy requirements need higher energy intakes), definite conclusions about prevalence of macronutrient adequacy cannot be made. However, the Acceptable Macronutrient Distribution Range (AMDR) indicates a range that provides the essential nutrients for a particular energy source (fats, carbohydrates, protein) yet is associated with reduced risk of chronic diseases [47]. Because U.S. IOM dietary guidelines have been adopted by the South African government, EARs/AIs/AMDRs for pregnant women, aged 19 to 30, were considered appropriate and used to determine likely inadequacies among this population. 
Protocols and consent forms were approved by the University of New Mexico (Medical

School HRRC 96-209 and 00-422, and Main Campus IRB 9625), the NIH Office of Protection from Research Risks (OPRR), the Ethics Committee of the University of Cape Town, and a local, single-site assurance committee. All women provided active consent.

\section{RESULTS}

\subsection{Child and maternal characteristics}

Detailed demographic, growth, cognitive/behavioral results for the children in this sample (FASD and controls) have been presented elsewhere [18]. Randomly-selected control children were significantly taller, weighed more, had higher BMIs, larger heads, and much less dysmorphology than those children with FASD. Children with FASD performed significantly lower on verbal and non-verbal IQ tests, and had significantly more problem behaviors.

Maternal data in Table 1 indicate that mothers of children with FASD had significantly lower mean weight and BMI (24.9 vs 27.3, $\mathrm{p}=0.026$ ) than did mothers of controls. Mothers of children with FASD were two times more likely to reside in a rural area during the index pregnancy, which generally means lower SES $[8,14,48]$. On average, mothers of children with FASD had three fewer years of education (5.3 vs. 8.3, p<.001). Mothers who had a child with an FASD had higher gravidity, parity, averaged one year older at the birth of the index child, and were more likely to live with a partner, yet were not married $(\mathrm{p}=.040)$. All alcohol consumption variables in Table 1 are significantly different statistically between maternal groups. Bingeing in the index pregnancy is reported by $67.4 \%$ of mothers of children with an FASD and 9.5\% of the controls. Mothers of children with FASD were twice as likely to smoke than controls during pregnancy (74\% to 32\%). However, smoking in this community is a relatively low quantity behavior; smoking mothers average between 30 and 60 cigarettes per week $[8,15,16]$.

\subsection{Dietary intake adequacies}

Maternal BMI is a useful indicator of usual adequate energy intake (relative to usual energy expenditure) [47]. BMIs within the normal range $\left(18.5<\mathrm{BMI}<25 \mathrm{~kg} / \mathrm{m}^{2}\right)$ indicate energy intake was adequate for $46.8 \%$ of all mothers; $51.6 \%$ exceeded requirements. A majority of the macronutrient intakes met or exceeded needs such as: AMDR for total fat $(60.9 \%)$, carbohydrate (65.6\%), and protein (91.4\%). But the data suggest that intake of many micronutrients was insufficient (Table 2 and Figure 1). More than half of all women in this study are likely inadequate ( $\angle \mathrm{EAR})$ for 12 of 15 micronutrients with established EARs. Likely micronutrient deficiencies (greater than $50 \%$ of women $<$ EAR) include vitamin A, D, $\mathrm{E}, \mathrm{C}$, thiamin, riboflavin, $\mathrm{B}_{6}$, calcium, magnesium, iron, and zinc. The majority of women likely do not have adequate intakes $(<\mathrm{AI})$ for vitamin $\mathrm{K}$, potassium, choline, omega-3 fatty acids, or fiber. These apparent deficiencies persist even after separating into the maternal groups. Using less stringent nutrient requirements (EARs for non-pregnant females, aged 19 to 30), more than half of all women are still likely inadequate for seven (vitamin A, D, E, C, folate, calcium, and magnesium) of the 15 micronutrients with EARs (data not shown). 
Vitamin K, potassium, choline and fiber still have observed means below AI for nonpregnant females, aged 19 to 30 .

The majority of women are likely adequate on vitamin $\mathrm{B}_{12}(56.2 \%>\mathrm{RDA})$, selenium $(71.1 \%>\mathrm{RDA})$, and sodium $(88.3 \%>\mathrm{RDA})$. A limited proportion of the sample is at risk for adverse effects (> Upper Tolerable Limit). While no women exceeded the upper tolerable limit (UL) for selenium (400ug), 56.2\% of mothers exceed the UL for sodium (2.3g). Vitamin $B_{12}$ does not have an established UL. Conclusions cannot be made about nutrient intakes that fall between EAR and RDA; thus no conclusions about the adequacy of niacin can be made.

Thus far, the results suggest that in our entire sample, there is a generalized inadequate intake for many micronutrients. We next asked whether there are dietary patterns that differentiated mothers of children with FASD from the mothers of the controls. The macronutrient intake patterns did not differ significantly between mothers of children with FASD and controls. Although mothers of children with FASD consumed, on average, less total fat, protein, and cholesterol, this did not reach statistical significance. There is a significant difference in the proportion of mothers who are likely inadequate ( $\angle E A R)$ for certain micronutrients (riboflavin, calcium, and magnesium) such that a greater proportion of mothers of children with an FASD are likely inadequate.

The mean dietary intake of riboflavin, calcium, docosapentanoic acid (DPA), and choline were significantly lower for mothers of children with FASD ( $p<.05$ ) (see Figure 1). Docosahexanoic acid (DHA) approached significance $(\mathrm{p}=.072)$ and EPA was also lower for mothers of children with FASD, but statistical significance was not reached at alpha .05 for either of these latter two nutrients or for omega-3 fatty acids overall.

Table 3 presents an assessment of the similarity of the diet at interview with intake during the mother's pregnancy with the index child. It is expected that most women would consume more food during pregnancy, and, within each maternal group, a greater proportion reported consuming more food during the index pregnancy than at the time of the interview. However the proportion of mothers of children with FASD who ate about the same was significantly more than that of controls ( $\mathrm{p}=.049)$, and the population who ate less was significantly higher $(p=.036)$ than controls. Less than $2 \%$ of the mothers of controls and $3.2 \%$ of mothers with children with an FASD reported being hungry or lacking sufficient money for food during their pregnancy, which is not statistically significant.

\subsection{Association between maternal dietary intake and alcohol consumption}

Table 4 correlations indicate that maternal intake of calcium and riboflavin are significantly, negatively associated with maternal drinking in all trimesters $(\mathrm{r}=-.237$ and $\mathrm{r}=-.196)$, drinks per drinking day ( $\mathrm{r}=-.252$ and $\mathrm{r}=-.179)$, bingeing 3 or more drinks per occasion $(\mathrm{r}$ $=-.294$ and $\mathrm{r}=-.193)$, and bingeing 5 or more drinks per occasion $(\mathrm{r}=-.225$ and $\mathrm{r}=-$. 230). Choline, DPA, and DHA were negatively correlated with alcohol consumption, although none of the correlations reached statistical significance. The percentage of calories from saturated fatty acids correlated negatively and significantly with three of five drinking measures. 


\section{DISCUSSION}

\subsection{Environmental and nutritional influences on fetal development}

The very high prevalence of FASD in this ZA community results from a unique confluence of variables reflecting the effect of drinking on a highly vulnerable population in terms of historic, socioeconomic, and nutritional factors [48-50]. In this study, there were significant differences in demographic and socioeconomic variables, and nutritional intake that all appear to negatively impact fetal development over and above the effects of alcohol intake by mothers.

The majority of women were likely inadequate ( $\angle \mathrm{EAR})$ on most nutrients and not meeting DRI. The majority of all women were likely deficient on vitamin A, D, E, K, C, thiamin, riboflavin, vitamin $\mathrm{B}_{6}$, total folate, calcium, magnesium, iron, zinc, potassium, and choline. Researchers have demonstrated that nutritional deficiencies in pregnant animals can lead to altered morphology, physiology, and performance in offspring [51]. Deficiencies in these nutrients can negatively impact acute and chronic diseases in infants and children.

Suboptimal or marginal nutrient intakes observed in this sample are not typically associated with overt disease, but the overall nutrient intake of these mothers is likely a contributing factor to poor fetal development in the presence of a known teratogen, alcohol. Furthermore, inadequacy of specific vitamin intake among the group of mothers bearing children with FASD may invite and justify further inquiry into any specific association or role they may play in the development of traits of FASD, both physical and cognitive/behavioral.

Calcium was most deficient among mothers of children with FASD, and it plays a vital role in bone formation, neurotransmitter release, gene expression regulation, and signaling processes. When maternal dietary calcium intake is low, fetal bone development and mineralization may be compromised [52]. Furthermore, both chronic and acute alcohol consumption reduce circulating osteocalcin, a protein that interacts with calcium and is required for bone formation. Early clinical studies of FAS indicated that bone age was deficient in children with many severe cases of FAS [53].

Omega-3 fatty acids during pregnancy are essential for development of neural tissue and visual function. Although there are no DRI for these individual omega-3 fatty acids, the IOM recommends that about $10 \%$ of total omega-3 intake should come from DPA and EPA [54]. For pregnant women, this equates to about 0.14 grams/day, and the intake of mothers of children with FASD in this ZA sample is far below the IOM recommendation for DPA and EPA. Omega-3 fatty acid intakes are believed to be most critical during the last trimester of pregnancy and the first few months of life when rapid accretion occurs in the central nervous system. The lack of omega-3's directly and adversely affects fetal brain development and cognitive function later in life $[55,56]$. DHA is particularly important in cognitive development [57,58], and a recent study suggests that supplementation with DHA improves birth weight and gestation duration [59]. EPA also shows promise as a bioactive nutrient to promote brain development and function [60], and its mechanisms of action on various developmental processes mirror those of DHA [61,62]. Much less is known about the biological function of DPA, and given the very low intake of DPA in mothers of children with FASD, understanding the biological significance of this finding is important. 
Low levels of riboflavin intake in mothers of children with FASD are problematic for energy production and development, as riboflavin is needed to convert vitamin $\mathrm{B}_{6}$ and folate into useable forms. Vitamin $\mathrm{B}_{6}$ plays a role in certain gene expressions and neurotransmitter synthesis (serotonin, epinephrine, norepinephrine, and gamma-Aminobutyric acid). While, folate is a major requirement for brain and spinal cord development as well as regulation of gene expressions specifically by silencing certain sequences, riboflavin also plays a role in brain development [63-65].

Choline intake, also significantly lower in mothers of children with FASD, serves as an essential nutrient required for most cellular functions [66]. Choline deficiency during pregnancy and lactation may cause deficient motor function and memory in the offspring [32,51]. Multiple lines of evidence point towards a critical role of choline in brain development and cognition [67].

The majority of women were likely consuming adequate amounts of vitamin $\mathrm{B}_{12}$ and selenium. While the mean intake of vitamin $\mathrm{B}_{12}$ and selenium are higher than reported elsewhere $[68,69]$, dietary staples in South Africa have been shown to be high in selenium [70]. While 56.2\% mothers exceed the UL for sodium (2.3g) and are at risk for adverse effects, the mean intake is below the typical US diet ( 4000 mg/day).

\subsection{Alcohol complicates the nutrition scenario}

Alcohol passes freely across the placental barrier. Deficient nutritional status and alcohol interact, thus compounding the independent teratogenic effect of alcohol [71,72]. In addition to alcohol's influence on bioavailability of nutrients, drinking measures in this sample were associated with overall decreased nutrient intake for multiple nutrients, particularly with calcium, riboflavin, and percent of calories from saturated fatty acids (SFA). With patterns of heavy episodic (binge) drinking being the most harmful to the fetus [8-10,36,73,74], lighter (lower BMI) women from this exact community population who binge drink have been shown to be less able to eliminate alcohol via first-pass metabolism allowing more alcohol to cross the placenta [75]. Conversely, in heavier mothers the additional adipose tissue helps distribute the alcohol, and therefore, protects the fetus. The rate of alcohol metabolism is also much slower in the fetus causing the alcohol to remain in the fetal body and amniotic fluid longer than in the mother. In animal models, undernutrtion and alcohol consumption lead to impaired ability to metabolize alcohol, increased Blood Alcohol Concentration (BAC), and decreased maternal growth hormone levels, all of which negatively impact the offspring [71]. Therefore, it is likely that alcohol-induced fetal growth retardation is potentiated by inadequate nutrient intake and smaller body size.

\subsection{Limitations}

The major limitation of this study is that dietary intake information was not collected in the prenatal period of the index child, but for a 24-hour period seven years later. Although our questions attempted to link the data to the pregnancy, the change in diet over the years and problems of recall to the time of pregnancy could negatively impact the study. Underreporting is common with 24-hour dietary recalls, as participants have imperfect memory of consumption. On the other hand, time-line, follow back alcohol inventories are 
robust in their accuracy for many years [76,77]. Given the individual variation, determining adequacy is not precise; however, the nutrient intakes were analyzed as outlined by the IOM recommendations for DRI $[47,78]$. Furthermore, the small sample of children with an FASD makes it difficult to generalize these findings. But the overall findings indicate that most women in this community are deficient on intake of many micronutrients. Also the data associating nutrient intake with drinking measures and low BMI with the likelihood of a birth of a child with FASD are provocative.

A second limitation is that adequate diets, better living conditions, more stimulating conditions, and cessation of drinking may combine, both prenatally and postpartum, for better child outcomes in ways that we cannot fully understand from these types of analyses. While individual-level environmental conditions have been associated with an FASD birth outcome $[49,50]$, changing these conditions in the short-term is difficult, over time an improvement in social conditions may result in improved birth outcomes. It should also be noted that the data were collected prior to the ZA food fortification legislation implemented in October 2003. However, an evaluation of the pre-fortification and post-fortification micronutrient intake of ZA women found that $>70 \%$ of lactating women did not meet the EAR for fortified nutrients: zinc, vitamin $\mathrm{A}$, riboflavin, or $\mathrm{B}_{6}$ and $>80 \%$ had inadequate intakes for non-fortified nutrients: calcium, vitamin $\mathrm{B}_{12}, \mathrm{C}$, and $\mathrm{D}$ [65]. Others have found similar post-fortification deficiencies [68]. This suggests that monitoring the micronutrient status of women of childbearing age should be a public health priority not only to help improve the outcome of alcohol-exposed pregnancies, but also to improve general population outcomes.

A third limitation is a lack of blood samples that could have been used to validate the findings of the 24-hour dietary recall. This study used only the NDSR database to estimate the nutritional composition of South African foods. While it is common to use USdeveloped nutrient software to estimate micronutrient composition of foods, and South African health officials have adopted US standards, some bias may have been introduced by using an American database in this particular South African context. Blood analysis would also allow for more definitive conclusions regarding maternal nutrient deficiencies. But, given the high proportion of mothers who were below EAR, it is likely that the mothers are truly deficient and potentially the children may also have been deficient.

\section{CONCLUSIONS}

The dietary intake profile and nutritional deficiencies in this sample are consistent with other studies in ZA. The proportion of women likely deficient on most micronutrients suggests nutritional interventions are warranted for women of childbearing age. While better living and more stimulating conditions in a majority of households in this community will be difficult to change in a short period of time, better diets and nutritional supplementation can be achieved quite quickly. These approaches may be promising for public health prevention and intervention to minimize FASD in ZA and in other populations of the world. 


\section{Acknowledgments}

Funding was provided by the NIAAA (RO1 AA09440, UO1 AA11685, and RO1/U01 AA 015134), the National Center on Minority Health Disparities (NCMHD), and the Foundation for Alcohol Related Research (FARR). We thank the women who provided the information for this study. We are also indebted to Denis Viljoen and Chris Shaw of FARR and to Loretta Hendricks, Leana Marais, and Dicky Naude who participated in the collection of the data. We also thank University of New Mexico student employees Jason Buchan, Eileen Estrada, Matthew Hernandez, Gloria King, Megan Malavoz, Cindy Michelman, Gwyneth Moya, Robert Newcomb, Ethel Nicdao, Jenny Romero, and Audrey Solimon who assisted with data entry. David Buckley assisted in preparing this manuscript. Jason Blankenship participated in the data management, statistical analysis, and preparation of this manuscript prior to his untimely death on October 29, 2013.

\section{REFERENCES}

1. Charlton KE, Rose D. Prevalence of household food poverty in South Africa: results from a large, nationally representative survey. Public Health Nutr. 2002; 5:383-389. [PubMed: 12003648]

2. Greer J, Thorbecke E. Food poverty profile applied to Kenyan smallholders. Economic Development and Cultural Change. 1986; 35:115-141.

3. Ravallion M. Food prices and rural poverty. Econ Polit Week. 1998; 33:1870-1871.

4. Rose D, Charlton KE. Quantitative indicators from a food expenditure survey can be used to target the food insecure in South Africa. J Nutr. 2002; 132:3235-3242. [PubMed: 12421834]

5. Lemke S, Vorster HH, van Rensburg NS, Ziche J. Empowered women, social networks and the contribution of qualitative research: broadening our understanding of underlying causes for food and nutrition insecurity. Public Health Nutr. 2003; 6:759-764. [PubMed: 14641946]

6. Oldewage-Theron WH, Dicks EG, Napier CE. Poverty, household food insecurity and nutrition: coping strategies in an informal settlement in the Vaal Triangle, South Africa. Public Health. 2006; 120:795-804. [PubMed: 16824562]

7. Croxford J, Viljoen D. Alcohol consumption by pregnant women in the Western Cape. S Afr Med J. 1999; 89:962-965. [PubMed: 10554632]

8. May PA, Gossage JP, Brooke LE, Snell CL, Marais AS, Hendricks LS, et al. Maternal risk factors for fetal alcohol syndrome in the Western cape province of South Africa: a population-based study. Am J Public Health. 2005; 95:1190-1199. [PubMed: 15933241]

9. May PA, Gossage JP, Marais AS, Hendricks LS, Snell CL, Tabachnick BG, et al. Maternal risk factors for fetal alcohol syndrome and partial fetal alcohol syndrome in South Africa: a third study. Alcohol Clin Exp Res. 2008; 32:738-753. [PubMed: 18336634]

10. May PA, Blankenship J, Marais AS, Gossage JP, Kalberg WO, et al. Maternal alcohol consumption producing fetal alcohol spectrum disorders (FASD): quantity, frequency, and timing of drinking. Drug Alcohol Depend. 2013; 133:502-512. [PubMed: 23932841]

11. South African Vitamin A Consultative Group. Anthropometric, vitamin A, iron and immunisation coverage status in children aged 6-71 months in South Africa. South African Medical Journal. 1994; 86:354-357.

12. le Roux IM, le Roux PJ. Survey of the health and nutrition status of a squatter community in Khayelitsha. S Afr Med J. 1991; 79:500-503. [PubMed: 2020895]

13. Kruger A, Lemke S, Phometsi M, Van't Riet H, Pienaar A, Kotze G. Poverty and household food security of black South African farm workers: the legacy of social inequalities. Public Health Nutr. 2006; 9:830-836. [PubMed: 17010247]

14. May PA, Brooke L, Gossage JP, Croxford J, Adnams C, Jones KL, et al. Epidemiology of fetal alcohol syndrome in a South African community in the Western Cape Province. Am J Public Health. 2000; 90:1905-1912. [PubMed: 11111264]

15. May PA, Gossage JP, Marais AS, Adnams CM, Hoyme HE, Jones KL, et al. The epidemiology of fetal alcohol syndrome and partial FAS in a South African community. Drug Alcohol Depend. 2007; 88:259-271. [PubMed: 17127017]

16. May PA, Blankenship J, Marais AS, Gossage JP, Kalberg WO, Barnard R, et al. Approaching the Prevalence of the Full Spectrum of Fetal Alcohol Spectrum Disorders in a South African Population-Based Study. Alcohol Clin Exp Res. 2013; 37:818-830. [PubMed: 23241076] 
17. Urban M, Chersich MF, Fourie LA, Chetty C, Olivier L, Viljoen D. Fetal alcohol syndrome among grade 1 schoolchildren in Northern Cape Province: prevalence and risk factors. S Afr Med J. 2008; 98:877-882. [PubMed: 19177895]

18. Viljoen DL, Gossage JP, Brooke L, Adnams CM, Jones KL, Robinson LK, et al. Fetal alcohol syndrome epidemiology in a South African community: a second study of a very high prevalence area. J Stud Alcohol. 2005; 66:593-604. [PubMed: 16331845]

19. May PA, Gossage JP, Kalberg WO, Robinson LK, Buckley D, Manning M, et al. Prevalence and epidemiologic characteristics of FASD from various research methods with an emphasis on recent in-school studies. Dev Disabil Res Rev. 2009; 15:176-192. [PubMed: 19731384]

20. Ramchandani VA, Kwo PY, Li TK. Effect of food and food composition on alcohol elimination rates in healthy men and women. J Clin Pharmacol. 2001; 41:1345-1350. [PubMed: 11762562]

21. Sedman AJ, Wilkinson PK, Sakmar E, Weidler DJ, Wagner JG. Food effects on absorption and metabolism of alcohol. J Stud Alcohol. 1976; 37:1197-1214. [PubMed: 979272]

22. Voltz HH, Baudrexel A, Dietrich W. Quantitative study on alcohol excretion by the animal organism under varied conditions, III: Effect of various degrees of fullness of the gastro-intestinal tract on alcohol exretion in urine and respiration. Archives of General Physiology. 1912; 145:210 228.

23. Breslow RA, Guenther PM, Juan W, Graubard BI. Alcoholic beverage consumption, nutrient intakes, and diet quality in the US adult population, 1999-2006. J Am Diet Assoc. 2010; 110:551562. [PubMed: 20338281]

24. Cogswell ME, Weisberg P, Spong C. Cigarette smoking, alcohol use and adverse pregnancy outcomes: implications for micronutrient supplementation. J Nutr. 2003; 133:1722S-31.

25. Gloria L, Cravo M, Camilo ME, Resende M, Cardoso JN, et al. Nutritional deficiencies in chronic alcoholics: relation to dietary intake and alcohol consumption. Am J Gastroenterol. 1997; 92:485489. [PubMed: 9068475]

26. Keen CL, Uriu-Adams JY, Skalny A, Grabeklis A, Grabeklis S, Green K, et al. The plausibility of maternal nutritional status being a contributing factor to the risk for fetal alcohol spectrum disorders: the potential influence of zinc status as an example. Biofactors. 2010; 36:125-123. [PubMed: 20333752]

27. Norton R. Maternal nutrition during pregnancy as it affects infant growth, development and health. SCN News. 1994; (11):10-14. [PubMed: 12288228]

28. Klinger K. The nutritional status of pregnant women in relation to alcohol consumption during pregnancy, and pregnancy outcome. 2004

29. Faber M, Benade AJ. Nutritional status and dietary practices of 4-24-month-old children from a rural South African community. Public Health Nutr. 1999; 2:179-185. [PubMed: 10447246]

30. Rufer ES, Tran TD, Attridge MM, Andrzejewski ME, Flentke GR, Smith SM. Adequacy of Maternal Iron Status Protects against Behavioral, Neuroanatomical, and Growth Deficits in Fetal Alcohol Spectrum Disorders. PLoS One. 2012; 7:e47499. [PubMed: 23094056]

31. Bekdash RA, Zhang C, Sarkar DK. Gestational Choline Supplementation Normalized Fetal Alcohol-Induced Alterations in Histone Modifications, DNA Methylation, and Proopiomelanocortin (POMC) Gene Expression in beta-Endorphin-Producing POMC Neurons of the Hypothalamus. Alcohol Clin Exp Res. 2013; 7:1133-1142. [PubMed: 23413810]

32. Thomas JD, La Fiette MH, Quinn VR, Riley EP. Neonatal choline supplementation ameliorates the effects of prenatal alcohol exposure on a discrimination learning task in rats. Neurotoxicol Teratol. 2000; 22:703-711. [PubMed: 11106863]

33. Hutson JR, Stade B, Lehotay DC, Collier CP, Kapur BM. Folic acid transport to the human fetus is decreased in pregnancies with chronic alcohol exposure. PLoS One. 2012; 7:e38057. [PubMed: 22666445]

34. Ieraci A, Herrera DG. Nicotinamide protects against ethanol-induced apoptotic neurodegeneration in the developing mouse brain. PLoS Med. 2006; 3:e101. [PubMed: 16478293]

35. Goh YI, Bollano E, Einarson TR, Koren G. Prenatal multivitamin supplementation and rates of congenital anomalies: a meta-analysis. J Obstet Gynaecol Can. 2006; 28:680-689. [PubMed: 17022907] 
36. Viljoen D, Croxford J, Gossage JP, Kodituwakku PW, May PA. Characteristics of mothers of children with fetal alcohol syndrome in the Western Cape Province of South Africa: a case control study. J Stud Alcohol. 2002; 63:6-17. [PubMed: 11925060]

37. Adnams CM, Kodituwakku PW, Hay A, Molteno CD, Viljoen D, May PA. Patterns of cognitivemotor development in children with fetal alcohol syndrome from a community in South Africa. Alcohol Clin Exp Res. 2001; 25:557-562. [PubMed: 11329496]

38. Kalberg WO, May PA, Blankenship J, Buckley D, Gossage JP, Adnams CM. A practical testing battery to measure neurobehavioral ability among children with FASSD. Int J Alcohol Drug Res. 2013; 2:51-60.

39. Stratton, K.; Howe, C.; Battaglia, F. Fetal Alcohol Syndrome: Diagnosis, Epidemiology, Prevention, and Treatment (Institute of Medicine). Washington, DC: National Academy Press; 1996.

40. Hoyme HE, May PA, Kalberg WO, Kodituwakku P, Gossage JP, Trujillo PM, et al. A practical clinical approach to diagnosis of fetal alcohol spectrum disorders: clarification of the 1996 institute of medicine criteria. Pediatrics. 2005; 115:39-47. [PubMed: 15629980]

41. Sobell LC, Agrawal S, Annis H, Ayala-Velazquez H, Echeverria L, Leo GI, et al. Cross-cultural evaluation of two drinking assessment instruments: alcohol timeline followback and inventory of drinking situations. Subst Use Misuse. 2001; 36:313-331. [PubMed: 11325169]

42. Sobell LC, Sobell MB, Leo GI, Cancilla A. Reliability of a timeline method: assessing normal drinkers' reports of recent drinking and a comparative evaluation across several populations. $\mathrm{Br} \mathrm{J}$ Addict. 1988; 83:393-402. [PubMed: 3395719]

43. Kaskutas LA, Graves K. Pre-pregnancy drinking: how drink size affects risk assessment. Addiction. 2001; 96:1199-1120. [PubMed: 11487425]

44. Kaskutas LA, Kerr WC. Accuracy of photographs to capture respondent-defined drink size. J Stud Alcohol Drugs. 2008; 69:605-610. [PubMed: 18612577]

45. Charlton KE, Bourne LT, Steyn K, Laubscher JA. Poor nutritional status in older black South Africans. Asia Pac J Clin Nutr. 2001; 10:31-38. [PubMed: 11708606]

46. Buzzard, M. 24-Hour dietary recall and food record methods. In: Willett, W., editor. Nutritional Epidemiology. New York: Oxford University Press; 1998.

47. Institute of Medicine. Dietary Reference Intakes: essential guide to nutrient requirements. Washington, DC: National Academies Press; 2006.

48. May PA, Tabachnick BG, Gossage JP, Kalberg WO, Marais AS, Robinson LK, et al. Maternal risk factors predicting child physical characteristics and dysmorphology in fetal alcohol syndrome and partial fetal alcohol syndrome. Drug Alcohol Depend. 2011; 119:18-27. [PubMed: 21658862]

49. May PA, Gossage JP, White-Country M, Goodhart K, Decoteau S, Trujillo PM, et al. Alcohol consumption and other maternal risk factors for fetal alcohol syndrome among three distinct samples of women before, during, and after pregnancy: the risk is relative. Am J Med Genet C Semin Med Genet. 2004; 127C:10-12. [PubMed: 15095467]

50. May PA, Tabachnick B, Gossage JP, Kalberg WO, Marais AS, Robinson LK, Manning M, et al. Maternal factors predicting cognitive and behavioral characteristics of children with fetal alcohol spectrum disorders. J Dev Behav Pediatr. 2013; 34:314-325. [PubMed: 23751886]

51. Thomas JD, Warren KR, Hewitt BG. Fetal alcohol spectrum disorders: From research to policy. Alcohol Research \& Health. 2010; 33:118-126. [PubMed: 23579942]

52. Chang SC, O'Brien KO, Nathanson MS, Caulfield LE, Mancini J, Witter FR. Fetal femur length is influenced by maternal dairy intake in pregnant African American adolescents. Am J Clin Nutr. 2003; 77:1248-1254. [PubMed: 12716679]

53. Smith DF, Sandor GG, MacLeod PM, Tredwell S, Wood B, Newman DE. Intrinsic defects in the fetal alcohol syndrome: studies on 76 cases from British Columbia and the Yukon Territory. Neurobehav Toxicol Teratol. 1981; 3:145-152. [PubMed: 7195990]

54. Kris-Etherton PM, Grieger JA, Etherton TD. Dietary reference intakes for DHA and EPA. Prostaglandins Leukot Essent Fatty Acids. 2009; 81:99-104. [PubMed: 19525100]

55. Bradbury J. Docosahexaenoic acid (DHA): an ancient nutrient for the modern human brain. Nutrients. 2011; 3:529-554. [PubMed: 22254110] 
56. Huffman SL, Harika RK, Eilander A, Osendarp SJ. Essential fats: how do they affect growth and development of infants and young children in developing countries? A literature review. Matern Child Nutr. 2011; 7(Suppl 3):44-65. [PubMed: 21929635]

57. Innis SM. Dietary (n-3) fatty acids and brain development. J Nutr. 2007; 137:855-859. [PubMed: 17374644]

58. Innis SM. Omega-3 Fatty acids and neural development to 2 years of age: do we know enough for dietary recommendations? J Pediatr Gastroenterol Nutr. 2009; 48(Suppl 1):S16-S24. [PubMed: 19214053]

59. Carlson SE, Colombo J, Gajewski BJ, Gustafson KM, Mundy D, Yeast J, et al. DHA supplementation and pregnancy outcomes. Am J Clin Nutr. 2013; 97:808-815. [PubMed: 23426033]

60. Ryan AS, Astwood JD, Gautier S, Kuratko CN, Nelson EB, Salem N Jr, et al. Effects of long-chain polyunsaturated fatty acid supplementation on neurodevelopment in childhood: a review of human studies. Prostaglandins Leukot Essent Fatty Acids. 2010; 82:305-314. [PubMed: 20188533]

61. Cansev M, Wurtman RJ. Chronic administration of docosahexaenoic acid or eicosapentaenoic acid, but not arachidonic acid, alone or in combination with uridine, increases brain phosphatide and synaptic protein levels in gerbils. Neuroscience. 2007; 148:421-423. [PubMed: 17683870]

62. Luchtman DW, Song C. Cognitive enhancement by omega-3 fatty acids from child-hood to old age: findings from animal and clinical studies. Neuropharmacology. 2013; 64:550-565. [PubMed: 22841917]

63. Danielyan KE, Abramyan RA, Galoyan AA, Kevorkian GA. Vitamin B-complex initiates growth and development of human embryonic brain cells in vitro. Bull Exp Biol Med. 2011; 151:579_ 583. [PubMed: 22462050]

64. Fordyce MK, Driskell JA. Effects of riboflavin repletion during different developmental phases on behavioral patterns, brain nucleic acid and protein contents, and erythrocyte glutathione reductase activity of male rats. J Nutr. 1975; 105:1150-1156. [PubMed: 1159530]

65. Papathakis PC, Pearson KE. Food fortification improves the intake of all fortified nutrients, but fails to meet the estimated dietary requirements for vitamins A and B6, riboflavin and zinc, in lactating South African women. Public Health Nutr. 2012; 15:1810-1817. [PubMed: 22874138]

66. Corbin KD, Zeisel SH. Choline metabolism provides novel insights into nonalcoholic fatty liver disease and its progression. Curr Opin Gastroenterol. 2012; 28:159-165. [PubMed: 22134222]

67. Zeisel SH. Choline: critical role during fetal development and dietary requirements in adults. Annu Rev Nutr. 2006; 26:229-250. [PubMed: 16848706]

68. Kolahdooz F, Spearing K, Sharma S. Dietary adequacies among South African adults in rural KwaZulu-Natal. PLoS One. 2013; 8:e67184. [PubMed: 23825639]

69. Hattingh Z, Walsh CM, Bester CJ, Oguntibeju OO. An analysis of dietary micronutrient intakes in two age groups of black South African women. West Indian Med J. 2008; 57:431-437. [PubMed: 19565971]

70. Spearing K, Kolahdooz F, Lukasewich M, Mathe N, Khamis T, Sharma S. Nutritional composition of commonly consumed composite dishes from rural villages in Empangeni, KwaZulu-Natal, South Africa. J Hum Nutr Diet. 2013; 26:222-229. [PubMed: 23216447]

71. Shankar K, Hidestrand M, Liu X, Xiao R, Skinner CM, Simmen FA, et al. Physiologic and genomic analyses of nutrition-ethanol interactions during gestation: Implications for fetal ethanol toxicity. Exp Biol Med (Maywood). 2006; 231:1379-1397. [PubMed: 16946407]

72. Shankar K, Ronis MJ, Badger TM. Effects of pregnancy and nutritional status on alcohol metabolism. Alcohol Res Health. 2007; 30:55-59. [PubMed: 17718402]

73. Maier SE, West JR. Drinking patterns and alcohol-related birth defects. Alcohol Res Health. 2001; 25:168-174. [PubMed: 11810954]

74. West JR, Goodlett CR. Teratogenic effects of alcohol on brain development. Ann Med. 1990; 22:319-325. [PubMed: 2291839]

75. Khaole NC, Ramchandani VA, Viljoen DL, Li TK. A pilot study of alcohol exposure and pharmacokinetics in women with or without children with fetal alcohol syndrome. Alcohol Alcohol. 2004; 39:503-508. [PubMed: 15351745] 
76. Hannigan JH, Chiodo LM, Sokol RJ, Janisse J, Ager JW, et al. A 14-year retrospective maternal report of alcohol consumption in pregnancy predicts pregnancy and teen outcomes. Alcohol. 2010; 44:583-594. [PubMed: 20036487]

77. Czarnecki DM, Russell M, Cooper ML, Salter D. Fiver year reliability of self-reported alcohol consumption. J Stud Alcohol. 1990; 51:68-76. [PubMed: 2299853]

78. Institute of Medicine. Dietary reference intakes: applications in dietary assessment. Washington, DC: National Academies Press; 2000. 


\section{Highlights}

- Dietary intake of women in South Africa is compared to recommended intakes.

- For most nutrients, all mothers were significantly below Dietary Reference Intakes.

- Mothers of FASD children had significantly lower intakes of calcium, DPA, riboflavin, and choline than controls.

- Lower nutrient intake correlates with binge drinking.

- Nutritional inadequacies with prenatal alcohol exposure increase the risk for FASD. 


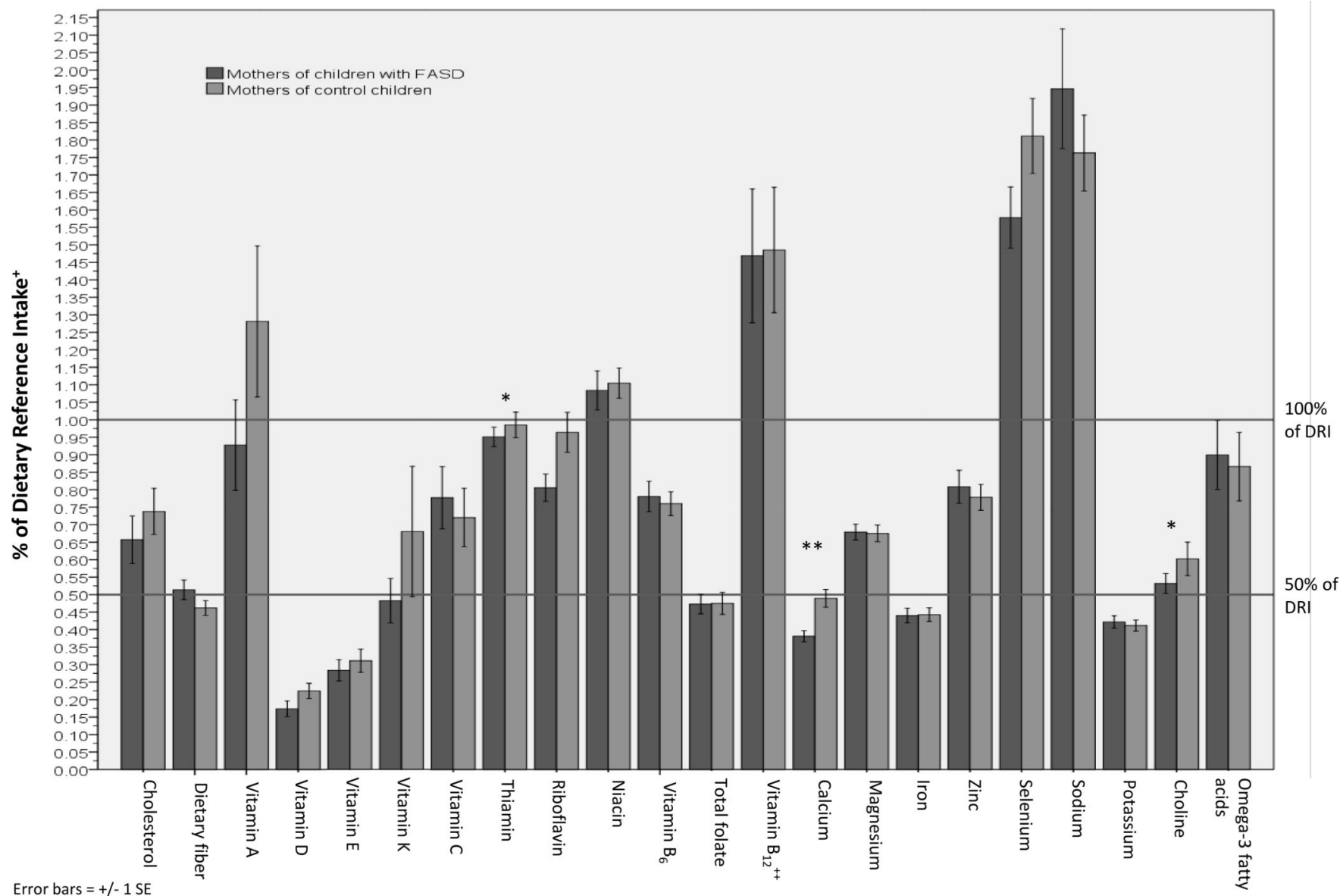

* Significant difference $(p<.05)$ between: Mothers of children with FASD and Mothers of control children

** Significant difference $(\mathrm{p}<.001)$ : Mothers of children with FASD and Mothers of control children

${ }^{+}$DRI: Estimated Average Requirement (EAR) for pregnant women, aged 19-30, used for: vitamin A, C, D, E, thiamin, riboflavin, niacin, vitamin $B_{6}$, folate, vitamin $B_{12}$, calcium, magnesium, iron, zinc, and selenium. Adequate Intake (Al) for pregnant women, aged 19-30, used for dietary fiber, vitamin K, sodium, potassium, choline, and omega-3 fatty acids. For cholesterol the IOM recommends cholesterol intake to be "as Low As Possible while consuming a nutritionally adequate diet". Less than $300 \mathrm{mg}$ per day is recommended by USDA.

${ }^{++}$One outlier removed.

Figure 1.

Percentage of Dietary Reference Intake (DRI) of Essential Nutrition of Mothers of Children with FASD and Controls from a Community in South Africa. 


\section{Table 1}

Maternal Demographic, Socioeconomic, Childbearing, Drinking and Smoking Variables for by FASD diagnosis

\begin{tabular}{|c|c|c|c|}
\hline Variable & $\begin{array}{c}\text { Mothers of Children } \\
\text { with FASD } \\
(\mathbf{n}=\mathbf{4 3})\end{array}$ & $\begin{array}{c}\text { Randomly-Selected } \\
\text { Control Mothers } \\
(\mathbf{n}=\mathbf{8 5})\end{array}$ & $\mathbf{P}$ \\
\hline \multicolumn{4}{|l|}{ Demographic and Socioeconomic Variables } \\
\hline Age on day of interview (yrs) - Mean (SD) & $35.4(6.1)$ & $34.4(6.7)$ & $.574^{a}$ \\
\hline Height $(\mathrm{cm})-$ Mean (SD) & $154.5(6.5)$ & $156.8(7.6)$ & $.088^{a}$ \\
\hline Weight $(\mathrm{kg})$ - Mean (SD) & $59.8(14.3)$ & $67.7(15.5)$ & $.006^{a}$ \\
\hline Body Mass Index (BMI) - Mean (SD) & $24.9(5.5)$ & $27.3(5.9)$ & $.026^{a}$ \\
\hline $\mathrm{BMI}<18.5 \mathrm{~kg} / \mathrm{m}^{2}(\%)$ & 4.7 & 0.0 & \\
\hline $18.5 \mathrm{~kg} / \mathrm{m}^{2} \leq \mathrm{BMI} \leq 25.0 \mathrm{~kg} / \mathrm{m}^{2}(\%)$ & 58.1 & 40.0 & \\
\hline $\mathrm{BMI}>25.0 \mathrm{~kg} / \mathrm{m}^{2}(\%)$ & 37.2 & 60.0 & $.012^{b}$ \\
\hline \multicolumn{4}{|l|}{ Residence during index pregnancy (\%) } \\
\hline Rural & 70.0 & 25.9 & \\
\hline Urban & 30.0 & 74.1 & $<.001^{b}$ \\
\hline Educational Attainment at interview (in yrs) - Mean (SD) & $5.3(3.2)$ & $8.3(2.4)$ & $<.001^{a}$ \\
\hline Current monthly income (Rands) - Mean (SD) & $1613.67(873)$ & $2433.86(1830)$ & $.006^{a}$ \\
\hline \multicolumn{4}{|l|}{ Childbearing Variables - (Current unless otherwise noted) } \\
\hline Gravidity - Mean (SD) & $3.6(1.5)$ & $2.8(1.1)$ & $.003^{a}$ \\
\hline Parity, pre- and full term - Mean (SD) & $3.4(1.4)$ & $2.7(1.0)$ & $.005^{a}$ \\
\hline Birth order of Index child - Mean (SD) & $2.7(1.5)$ & $2.0(1.2)$ & $.011^{a}$ \\
\hline Age at Birth of the Index Child - Mean (SD) & $27.3(6.1)$ & $25.8(6.6)$ & $.243^{a}$ \\
\hline \multicolumn{4}{|l|}{ Marital status during pregnancy with index child $(\%)$} \\
\hline Married & 27.9 & 30.6 & \\
\hline Unmarried, living with partner & 37.2 & 14.1 & \\
\hline Separated/Divorced/Widowed & 0.0 & 1.2 & \\
\hline Single & 34.9 & 54.1 & $.040^{b}$ \\
\hline \multicolumn{4}{|l|}{ Alcohol Consumption Variables } \\
\hline \multicolumn{4}{|l|}{ Drinking at the time of interview } \\
\hline Consumed alcohol in preceding week (\%) & 67.4 & 20.0 & $<.001^{b}$ \\
\hline Binged (3+) one or more days in preceding week $(\%)$ & 89.7 & 5.9 & $<.001^{b}$ \\
\hline Current \# of alcoholic drinks consumed per week - among drinkers - Mean (SD) & $13.90(10.41)$ & $4.81(4.98)$ & $.002^{a}$ \\
\hline \multicolumn{4}{|l|}{ During index pregnancy } \\
\hline Drank in $1^{\text {st }}$ trimester $(\%)$ & 90.7 & 22.4 & $<.001^{b}$ \\
\hline Drank in $2^{\text {nd }}$ trimester $(\%)$ & 90.7 & 15.3 & $<.001^{b}$ \\
\hline Drank in $3^{\text {rd }}$ trimester (\%) & 88.4 & 12.9 & $<.001^{b}$ \\
\hline Binged (3+) one or more days in during index pregnancy $(\%)$ & 67.4 & 9.4 & $<.001^{b}$ \\
\hline
\end{tabular}




\begin{tabular}{|c|c|c|c|}
\hline Variable & $\begin{array}{l}\text { Mothers of Children } \\
\text { with FASD } \\
(\mathbf{n}=\mathbf{4 3})\end{array}$ & $\begin{array}{c}\text { Randomly-Selected } \\
\text { Control Mothers } \\
(\mathbf{n}=\mathbf{8 5})\end{array}$ & $\mathbf{P}$ \\
\hline Binged (5+) one or more days in during index pregnancy $(\%)$ & 55.8 & 5.9 & $<.001^{b}$ \\
\hline Drinkers per drinking day during index pregnancy - Mean (SD) & 4.93 & 0.73 & $<.001^{a}$ \\
\hline \multicolumn{4}{|l|}{ Tobacco Use Variables } \\
\hline Smoked during index pregnancy $(\%)$ & 74.4 & 31.8 & $<.001^{a}$ \\
\hline Smoked and consumed alcohol during index pregnancy (\%) & 67.4 & 15.5 & $<.001^{a}$ \\
\hline Smoked and binged (3+) during index pregnancy $(\%)$ & 55.8 & 7.1 & $<.001^{b}$ \\
\hline Smoked and binged (5+) during index pregnancy $(\%)$ & 48.8 & 4.7 & $<.001^{b}$ \\
\hline
\end{tabular}

$a_{t \text { - test }}$

${ }^{b} \chi^{2}$ test 


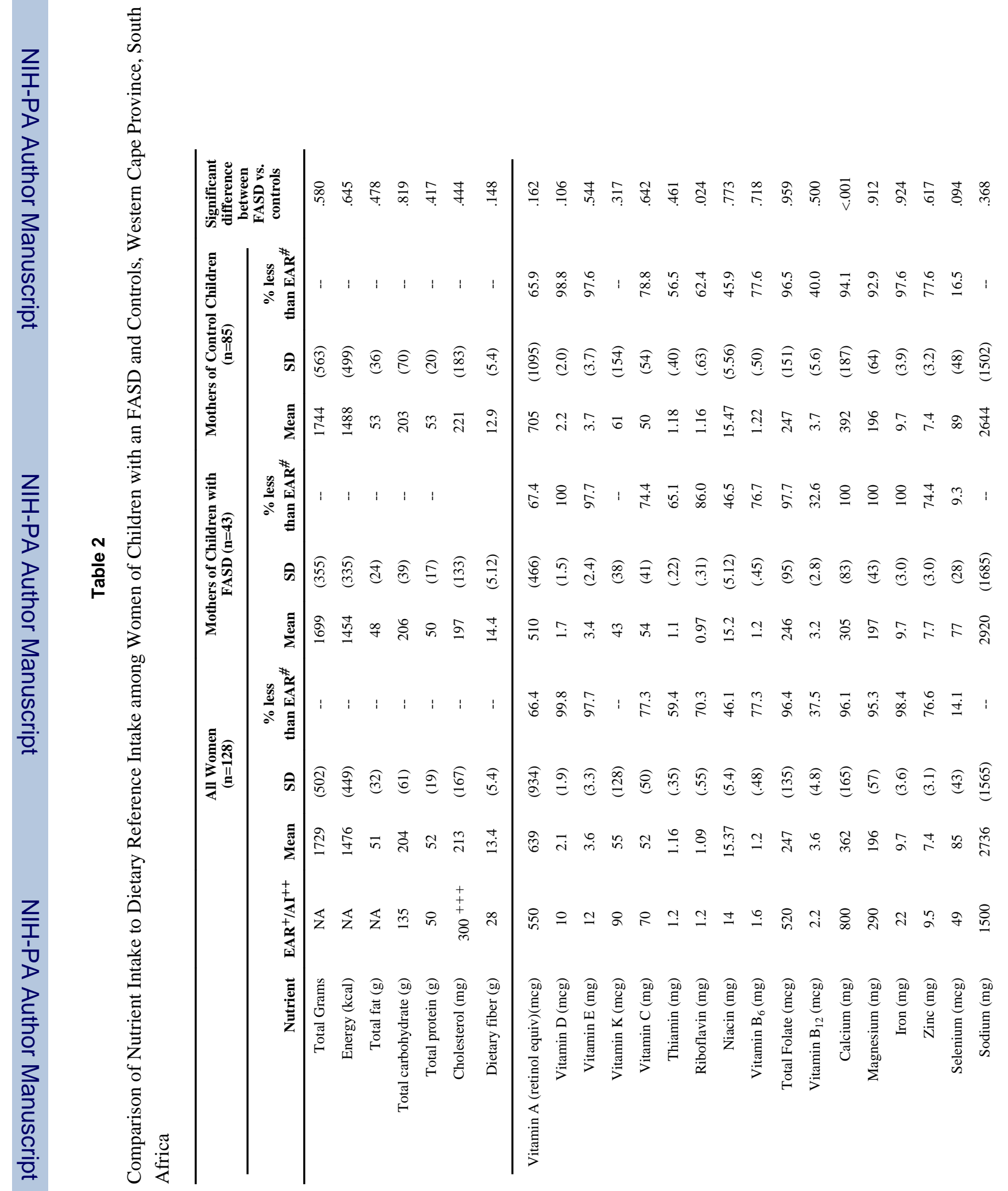




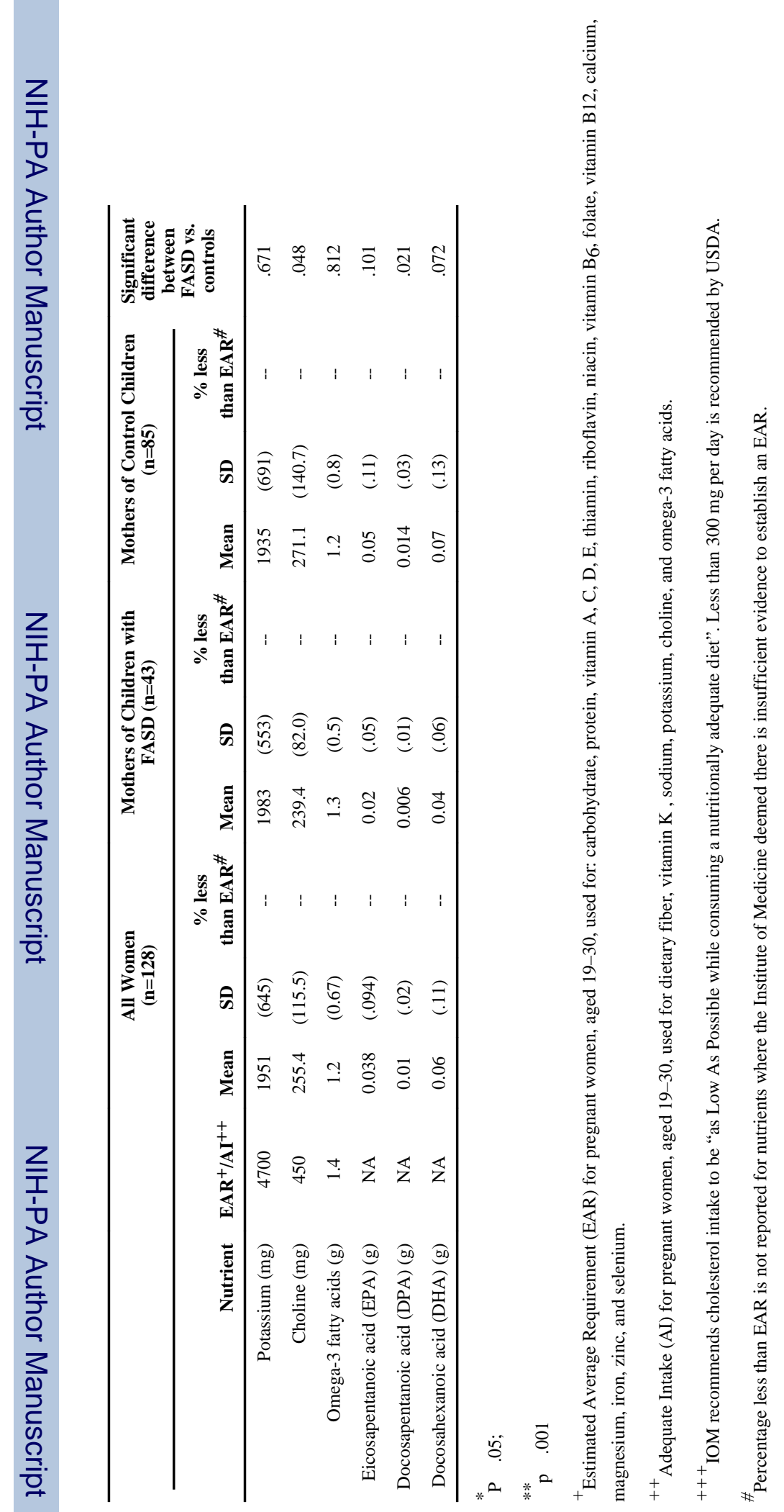

Reprod Toxicol. Author manuscript; available in PMC 2015 July 01. 


\section{Table 3}

Comparison of Dietary Intake at Time of Index Pregnancy to Current Intake For Women who Gave Birth to Children with an FASD and Randomly-selected Controls

\begin{tabular}{|c|c|c|c|c|}
\hline Variable & $\begin{array}{c}\text { Mothers of } \\
\text { Children } \\
\text { with FASD } \\
(n=43)\end{array}$ & $\begin{array}{c}\text { Control } \\
\text { Mothers } \\
(\mathbf{n}=\mathbf{8 5})\end{array}$ & $\begin{array}{c}\text { Difference in } \\
\text { Proportions Test } \\
\text { Result } \\
(z \text {-score })\end{array}$ & $p$ \\
\hline \multicolumn{5}{|c|}{ Similarity of diet on day of interview compared to time of pregnancy } \\
\hline Ate about the same $(\%)$ & 19.4 & 35.2 & 1.97 & .049 \\
\hline Ate less $(\%)$ & 38.7 & 20.4 & 2.10 & .036 \\
\hline Ate more $(\%)$ & 41.9 & 44.4 & 0.27 & .789 \\
\hline Often hungry during pregnancy? - (\% Yes $)$ & 3.2 & 1.8 & 0.45 & .649 \\
\hline \multicolumn{5}{|c|}{ One reason there was insufficient food in home during pregnancy - (\% Yes) } \\
\hline Not enough money & 3.1 & 0.0 & 1.16 & .246 \\
\hline No transportation to shops & 0.0 & 0.0 & -- & -- \\
\hline Other reasons & 0.0 & 3.8 & 1.82 & .069 \\
\hline
\end{tabular}




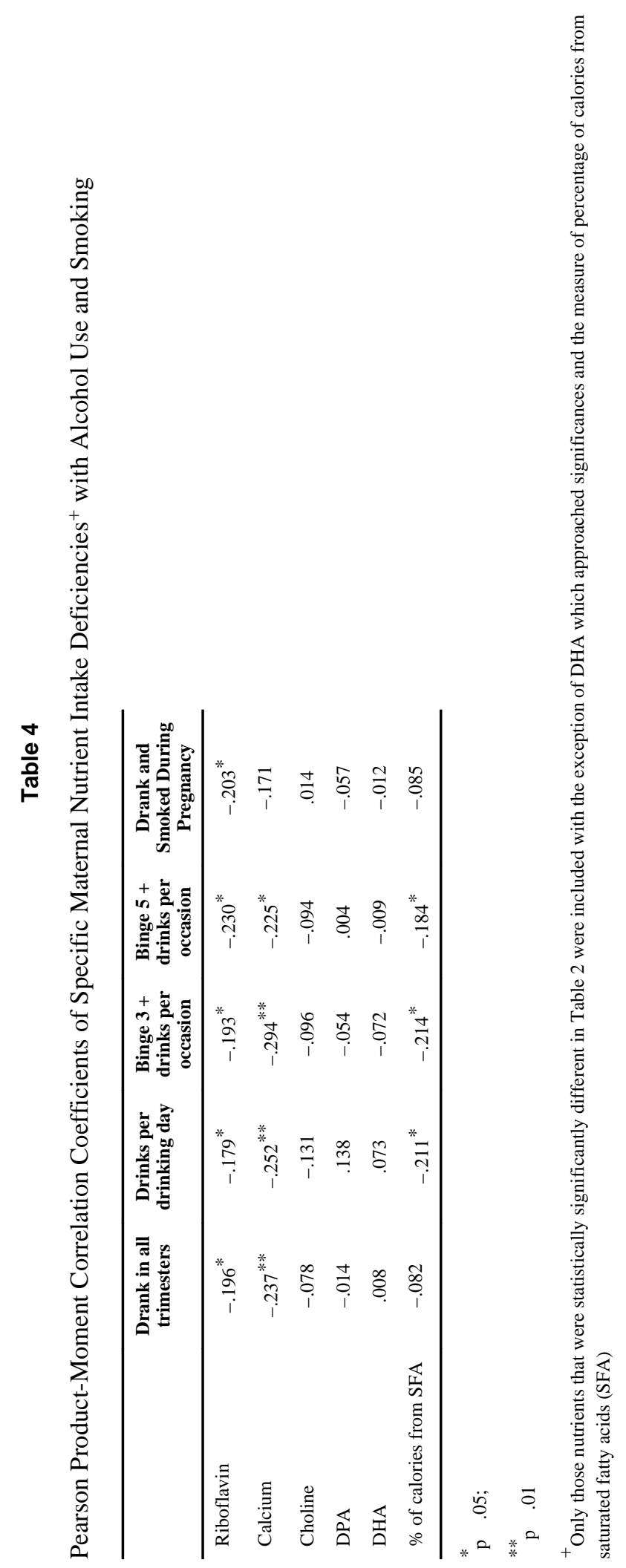

Reprod Toxicol. Author manuscript; available in PMC 2015 July 01. 